\title{
A Clinical Study Review-the Role of Active Fluidics and Torsional Phaco Power in Providing a Stable and Efficient Cataract Surgery Environment
}

\author{
Elizabeth Yeu \\ Eastern Virginia Medical School, Norfolk, VA, US
}

DOI: https://doi.org/10.17925/USOR.2018.11.1.32

$\mathrm{M}$ odifications to the phacoemulsification technique have continually improved surgical outcomes (and therefore visual outcomes) for our patients. While much has been written about the role of advanced technology in intraocular lenses and how they have helped to improve outcomes, there is less in the literature about the systems we use to deliver those outcomes. Active fluidics and torsional ultrasound are two innovations that have improved our ability to provide even better postoperative results to our cataract patients. The following article will explain why these two advances on the CENTURION ${ }^{\circledR}$ Vision System (Alcon) have made that machine my preferred phacoemulsification system.

\section{Keywords}

Phacoemulsification, fluidics, torsional ultrasound

Disclosure: Elizabeth Yeu is a consultant for Alcon $J \& J$ vision, and B\&L/Valeant. Alcon sponsored the publication of this promotional piece. The content has been independently peer reviewed by the uS Ophthalmic Review publication process.

Review Process: Double-blind peer review.

Acknowledgements: Independent medical writing assistance was provided by Michelle Dalton and supported by Alcon.

Authorship: All named authors meet the International Committee of Medical Journal Editors (ICMJE) criteria for authorship of this manuscript, take responsibility for the integrity of the work as a whole, and have given final approval to the version to be published. (C) The Author 2018

open Access: This article is published under the Creative Commons Attribution Noncommercial License, which permits any noncommercial use, distribution, adaptation, and reproduction provided the original author(s) and source are given appropriate credit.

Received: July 25, 2017

Accepted: November 30, 2017

Citation: US Ophthalmic Review. 2018;11(1):32-37

Corresponding Author: Elizabeth Yeu, 241 Corporate Blvd, Norfolk, VA, 23502, US. E: eyeu@vec2020.com

Support: The publication of this article was supported by Alcon.
Phacoemulsification is the gold standard for cataract surgery, ${ }^{1}$ and for good reason-over the decades it has been shown to be a safe and efficacious procedure that returns excellent visual outcomes to patients with cataracts. Every phacoemulsification system on the market can provide patients with excellent postoperative vision, with very low complication rates, however, they do differ in fluidic and torsional characteristics.

Since their introduction, the systems and the instrumentation cataract surgeons use have undergone modifications-some are now considered intrinsic to the success of the surgery, while others are considered incremental steps.

Among these improvements was the introduction of (first) gravity fluidics, followed by hyperpressurized, and subsequently active fluidics. Gravity fluidics was popular, but some thought that hyper-pressurized infusion would provide greater stability of the posterior capsule. The latest iteration on fluidics - active fluidics - may be considered a simple incremental advancement, but I would argue it will soon be recognized as an intrinsic one.

\section{Gravity and active fluidics overview}

In phacoemulsification systems that use gravity fluidics, a bottle containing a balanced salt solution is hung above the system, thereby using gravity to control and maintain eye volume during surgery. These systems have an inverse relationship between pressure and flow, whereby the more flow there is, the lower the pressure; this is particularly true when source pressure is constant. ${ }^{2}$

Active fluidics maintains the target pressure inside the eye by having variable input pressure as a result of the system compressing a compliant, balanced salt solution-filled bag between a motorized plate, thereby adjusting for variances in intraocular pressure (IOP) and reducing surge. ${ }^{2}$ In my hands, slowing the rate of eye pressurization means cataract removal can be performed at almost physiologic IOPS of $<40 \mathrm{mmHg}$. Keeping the IOP steady translates to a more consistently stable anterior chamber to work in, one that mitigates any type of surge that can occur from lens clearance, and is able to maintain an adequate amount of anterior chamber (AC) depth for the surgeon to perform the surgery safely. The CENTURION ${ }^{\circledR}$ Vision System (Alcon) uses "active fluidics" that uses a variable input pressure. The WHITESTAR Signature* Phacoemulsification System (Johnson \& Johnson Vision [Johnson \& Johnson purchased Abbott Medical Optics (AMO) in 2016; at the time of this study, the WHITESTAR Signature* Phacoemulsification System was manufactured 
and marketed by AMO]) uses gravity-based "fusion fluidics." The Stellaris Vision Enhancement System (Bausch \& Lomb) uses pressurized gravity-based "stable chamber fluidics." Each system has its benefits and detractors, but I prefer the CENTURION ${ }^{\circledR}$ Vision System for several reasons, and the literature supports my real-world, clinical observations.

For me, the improved fluidics in the CENTURION ${ }^{\circledR}$ Vision System has led to several clinical benefits, including decreased surgical times and a greater followability. This leads to a much more efficient nuclear disassembly with less overall ultrasound energy use. More importantly, this feature helps to normalize the potentially more difficult surgical cases because I can select a target IOP. The stable AC means that the iris does not "bounce" and the pupil size is maintained, an important benefit to prevent and mitigate floppy iris syndrome and those smaller pupil cases, such as are seen in eyes with pseudoexfoliation. The AC is more readily maintained in cases where this is a greater issue, particularly with "crowded," naturally shallow anterior chambers of the axial hyperopes, and the converse with overly deep eyes of the larger axial myopes. Lastly, the balanced and stable AC now maintains the space necessary to keep the posterior capsule back, which is particularly important in the disassembly of very dense lenses, where we have all experienced more problematic surges, and the potential capsule compromise as a result, with prior systems.

\section{What the data say}

In a laboratory study comparison of occlusion break surge on the CENTURION $^{\circledR}$ Vision System, INFINITI ${ }^{\circledR}$ Vision System (Alcon), and the WHITESTAR Signature* Phacoemulsification System (AMO) and vacuum rise time on the INFINITI ${ }^{\circledR}$ Vision System, WHITESTAR Signature* Phacoemulsification System, CENTURION ${ }^{\circledR}$ Vision System, and Stellaris Vision Enhancement System, the CENTURION ${ }^{\circledR}$ Vision System produced substantially less surge than the INFINITI ${ }^{\circledR}$ Vision System or WHITESTAR Signature* Phacoemulsification System. ${ }^{*}$ This held even with the highest preset aspiration vacuum level $(600 \mathrm{mmHg})$ and the lowest active fluidics pressure (targeting $40 \mathrm{mmHg}$, or about $54 \mathrm{~cm} \mathrm{H}_{2} \mathrm{O}$ ); the gravity fluidics systems on the INFINITI ${ }^{\circledR}$ Vision system and WHITESTAR Signature* Phacoemulsification System were $90 \mathrm{~cm} \mathrm{H}_{2} \mathrm{O}$. The authors further tested vacuum limits of $400 \mathrm{mmHg}$ and $600 \mathrm{mmHg}$ with typical $(30 \mathrm{cc} / \mathrm{min})$ and maximal $(60 \mathrm{cc} / \mathrm{min})$ flow rates. INFINITI ${ }^{\otimes}$ Vision System exceeded the 400 mmHg limit but no system achieved the 600 mmHg limit; ${ }^{3}$ Stellaris Vision Enhancement System had a slower rate of vacuum rise to both levels, but overall the rise times were similar between the systems. ${ }^{3}$

A small case series (five eyes; three patients) evaluated the CENTURION ${ }^{\circledR}$ Vision System system in the setting of nanophthalmos and found the CENTURION ${ }^{\circledR}$ Vision System rapidly responded (100 ms) to changes in IOP, minimized the surge volume, and returned the IOP to pre-occlusion status. ${ }^{4}$

\section{Longitudinal versus torsional modes}

Personalized medicine is beginning to become common practice in some specialties, even within ophthalmology in some retinal disease states, but cataract surgery has often been viewed as a straightforward procedure that needs little customization. The introduction of torsional phaco more than a decade ago and the combination of torsional with longitudinal techniques, however, may change minds.

In my opinion, torsional phacoemulsification was an intrinsic improvement over earlier generation systems. Traditional longitudinal systems only break up material when the tip moves forward, so half the energy is expended while the device is inactive (when the tip moves backwards). Longitudinal phaco tips have also been associated with reduced followability, whereas torsional minimizes chatter ${ }^{5}$ (more on that, below). The INFINITI ${ }^{\circledR}$ Vision system cuts lens material by using a torsional circular oscillation pattern (like turning a knob) rather than an in-out approach. ${ }^{6}$

I do appreciate what both longitudinal and torsional modes offer, and utilize both to my benefit during surgery. The less efficient Iongitudinal phaco allows me to occlude and build vacuum, without emulsifying through the nucleus, thus facilitating access to the first nuclear quadrant out of the crowded bag and into the center of the anterior chamber. I then switch to torsional mode within my quadrant removal setting, which allows me to efficiently disassemble the nucleus with less overall dissipated phaco energy.

\section{What the data say}

Numerous studies have compared torsional to traditional ultrasound technologies, with most finding torsional mode capable of lens removal with substantially lower phacoemulsification time and energy expended, with increased safety, and a reduction in endothelial cell loss. ${ }^{6-11}$

A coaxial torsional method has been shown to use less ultrasound power than a longitudinal method in eyes with grade 4 or 5 nuclear cataracts, but take longer, although the difference did not reach statistical significance. ${ }^{7}$ At 1 and 3 months, endothelial cell loss exceeded 35\% in both groups ( $n=35$ in each group), and those differences were not statistically significant.

The CENTURION ${ }^{\circledR}$ Vision System incorporates the OZi ${ }^{\circledR}$ Torsional Handpiece; Helvacioglu et al. showed the OZil ${ }^{\circledR}$ Intelligent Phaco (IP) torsional mode may provide more effective lens removal than a combined torsional/longitudinal ultrasound mode with a lower overall ultrasound time and less BSS volume use. ${ }^{8}$ The authors suggested the Ozil ${ }^{\circledR}$ would make "an ideal partner" for femtosecond laser-assisted cataract surgery procedures because of its safety and efficacy in emulsifying divided nucleus materials. ${ }^{8}$

Tognetto et al. compared intraoperative parameters and postoperative outcomes between the WHITESTAR Signature* Phacoemulsification System standard phaco handpiece or the Ellips* FX (AMO) phaco handpiece. While both handpieces were considered safe, the Ellips* FX showed better performance "and may be safer in lens removal, especially in hard cataract patients." ${ }^{12}$

Christakis et al. compared the intraoperative performance of the WHITESTAR Signature* Phacoemulsification System Ellips* FX (transversal technology), the $\mathrm{OZi}^{\circledR} \mathrm{IP}$, and Stellaris Vision Enhancement System (Iongitudinal technology) in 98 patients undergoing cataract surgery. ${ }^{13}$ The Stellaris Vision Enhancement System incorporates a foot pedal to allow independent control of phaco power and vacuum. The WHITESTAR Signature* ELLIPS* FX uses transversal technology and Iongitudinal movement, with both peristaltic and Venturi fluidics. The INFINITI ${ }^{\circledR}$ Vision system OZil IP uses torsional technology.13 Overall, the group found all three systems to be effective, without any significant intraoperative complications.

In the WHITESTAR Signature* Phacoemulsification System and Stellaris Vision Enhancement System groups, a straight tip was used, whereas a $45^{\circ}$ Kelman tip was used in the Ozil group. The mean total phaco needle 
time differed significantly between groups $(p=0.02)$, with the Ozil requiring the least amount of time (83 seconds), followed by transversal and then Iongitudinal technologies (99 and 110 seconds, respectively). This study found that with dense cataract the torsional group averaged less phaco needle time (104 seconds) than the transversal group (154 seconds; $p=$ not significant) and the longitudinal group (166 seconds; $p=0.01) .{ }^{13}$ There have been reports on "clogging" of the phaco tip during cataract removal when Ozil has been used, and that may increase heat buildup in and around the area of removal. ${ }^{14,15}$ However, these reports are few and far between.

Jensen et al. used porcine eyes to show the CENTURION ${ }^{\circledR}$ Vision System decreased chatter at higher power settings (linear up to 60\% power, and was almost nonexistent at 60\% power and higher), and suggested increasing efficiency allowed the vacuum to better engage the lens fragment on the phaco tip while minimizing the chatter. ${ }^{16}$ In a separate study on porcine lenses, Jensen et al. set the vacuum to $500 \mathrm{mmHg}$, aspiration at $35 \mathrm{~mL} / \mathrm{min}$, and torsional power at $60 \%$ on the CENTURION ${ }^{\circledR}$ Vision System. ${ }^{17}$ They also found a linear relationship between efficiency and IOP, where increasing IOP led to an increase in efficiency ( $2=0.5769, p=0.0176$ ). At IOPS $>50 \mathrm{~mm} \mathrm{Hg}$, chatter became almost nonexistent. Chatter and IOP were linearly related only at an IOP between $30 \mathrm{~mm} \mathrm{Hg}$ and 50 mmHg (R2=0.4506, p=0.0448).

\section{Energy and its effect on fluidics}

Cumulative dissipated energy (CDE) can vary by both surgeon and phacoemulsification technique, and even by surgical location (ambulatory surgical center compared to a hospital-based operating room). ${ }^{18}$ As greater experience is gained and more research is published, it is my belief that we will continue to find CDE is substantially lower with active fluidics on the CENTURION ${ }^{\circledR}$ Vision System, resulting in improved surgical efficiency.

\section{What the data say}

Solomon et al. compared CDE, aspiration fluid used, and aspiration time in eyes undergoing cataract surgery with the CENTURION ${ }^{\circledR}$ Vision System or the INFINITI ${ }^{\circledR}$ Vision System. ${ }^{19}$ In each parameter tested, the CENTURION ${ }^{\circledR}$ Vision System used significantly less than the INFINITI ${ }^{\circledR}$ Vision System. CDE was significantly lower with the active-fluidics configuration than with the gravity-fluidics configuration $(p<0.001)$. The active-fluidics configuration used significantly less aspiration fluid than the gravity-fluidics configuration $(p<0.001)$. Aspiration time was significantly shorter with the active-fluidics configuration than with the gravity-fluidics configuration ( $p<0.001)$.

A meta-analysis of published randomized clinical trials also found torsional mode to be superior for intraoperative parameters including ultrasound time and CDE, and in postoperative endothelial cell loss outcomes in patients with moderate to hard cataracts. ${ }^{11}$ In this analysis, a total of 1,765 patients and 1,759 eyes (870 treated with longitudinal phaco-mode, 889 with torsional phaco-mode) were included from seven studies. The ultrasound time and CDE values were found to be statistically significant in support of the torsional mode for both moderate and hard cataracts. The standardized mean difference (SMD) for moderate cataracts were -0.657 (95\% confidence interval [Cl] -0.834 to -0.560 ; $\mathrm{p}=0.000)$ and $-0.586(95 \% \mathrm{Cl},-0.724$ to $-0.449, \mathrm{p}=0.000)$ for ultrasound time and $C D E$, respectively.

In the five studies that reported it, mean ultrasound time was shorter in the torsional group than in the longitudinal group, and the SMD in ultrasound time was statistically significant (SMD=-0.708; 95\% Cl, -0.833 to $-0.584, p=0.00$ ).
In five studies that reported it, mean CDE was lower in the torsional group. SMD in cumulative dissipated energy was statistically significant (SMD=$0.533 ; 95 \% \mathrm{Cl},-0.656$ to $-0.409, \mathrm{p}=0.001$ ). There was no statistical difference in best corrected visual acuity outcomes.

Chen et al. retrospectively compared CDE between the CENTURION ${ }^{\circledR}$ Vision System and the INFINITI ${ }^{\circledR}$ Vision System in 2,017 cases with similar age, sex, and complication rates ( $p>0.05$ ) at a single center (five experienced surgeons). ${ }^{20}$ Each surgeon demonstrated a statistically significant reduction in CDE with CENTURION ${ }^{\circledR}$ Vision System versus INFINITI ${ }^{\circledR}$ Vision System (unadjusted average energy reduction of CDE with the CENTURION ${ }^{\circledR}$ Vision System was 4.971 [range 2.25-12.54] percent-seconds or 37\% [range 29$45 \%], p<0.001$ ] when compared to the INFINITI ${ }^{\circledR}$ Vision System). Of interest, the group also found that for every 10-year increase in patient age, there was a corresponding CDE increase of 2.38 unit $(p<0.001)$.

The Intrepid Balanced Tip, designed for torsional ultrasound, minimizes corneal stromal changes at the incision site, by reducing the amount of energy transmitted to the sleeve and incision site. ${ }^{20}$

More recently, Khokhar et al. compared the Intrepid Balanced Tip to a Kelman tip and found that mean total CDE, total US time, torsion amplitude, aspiration time, and fluid use were significantly lower with the Intrepid tip than with the Kelman tip. There was no significant difference in mean torsion use time between the two groups, although these values attained statistical significance in higher grades of cataract. ${ }^{?}$

Heat produced during phacoemulsification can result in direct corneal thermal damage or endothelial cell loss; Ryoo etal.compared heat production across three platforms: WHITESTAR Signature* Phacoemulsification System, INFINITI ${ }^{\circledR}$ Vision System with OZil, and Stellaris Vision Enhancement System. ${ }^{21}$ At all time points (beyond 0 seconds), temperatures were lower in the INFINITI ${ }^{\circledR}$ Vision System. Regardless of platform, higher aspiration flow rates resulted in cooler tips.

High-speed imaging confirmed that, while cavitation does not contribute significantly to emulsifying the lens, it does generate free radicals, which damage the corneal endothelium. Therefore, since torsional ultrasound produces fewer free radicals, there may be a protective effect of the technology. 22

More and more cataract surgeons are integrating femtosecond laserassisted cataract surgery (FLACS) technology to their practices, but little has been published comparing the mean CDE between conventional and FLACS platforms. The femtosecond laser can be used to fragment the lens, and some studies have suggested that, in turn, decreases the amount of energy used during the phacoemulsification portion of surgery. ${ }^{23}$ However, a Cochrane Library meta-analysis of 16 studies comparing FLACS to standard phacoemulsification "could not determine the equivalence or superiority" of FLACS. ${ }^{24}$ It is hoped that future studies will incorporate patient-reported outcomes (PROS). There are meta-analyses that have yielded more positive results. ${ }^{25}$ Twenty-four studies were analyzed $(n=4,903)$ by chen et al. ${ }^{25}$ Compared to conventional phacoemulsification, FLACS is a safer and more effective method for reducing endothelial cell loss and postoperative central corneal thickening as well as achieving better and faster visual rehabilitation and refractive outcomes. However, there is no difference 
in final CDVA and surgically induced astigmatism between the two groups. Further studies are warranted regarding visual outcomes. Some surgeons are getting their own internal data ready to publish regarding percentage of patients hitting $\pm 0.5 \mathrm{D}$ when FLACS is added. It will be exciting to see those results soon.

More recently, Yesilirmak et al. compared 570 eyes that underwent cataract surgery with the CENTURION ${ }^{\circledR}$ Vision System in conventional and FLACS surgery ( $n=232$ and $n=86$, respectively) or with the INFINITI ${ }^{\circledR}$ Vision System in conventional and FLACS surgery ( $n=193$ and $n=59$, respectively). ${ }^{23}$ The mean CDE was significantly lower in the femtosecond group than in the conventional group with both phaco platforms $\left(p=0.0008\right.$, CENTURION ${ }^{\circledR}$
Vision System platform; $\mathrm{p}=0.0003$, INFINITI ${ }^{\circledR}$ Vision System platform), and there was a trend toward lower CDE in the FLACS group as well. However, neither PROs nor visual outcomes were reported.

\section{Conclusion}

There is no doubt phacoemulsification machines are effective and safe to use; surgeon preference is often the deciding factor. The active fluidics and torsional components of the CENTURION ${ }^{\circledR}$ Vision System yield reduced CDE output compared to gravity-based systems, which, in turn, creates a safer, more stable surgery and quicker visual recovery for patients. In my hands, I have found the CENTURION ${ }^{\circledR}$ Vision System to be a better platform than other systems.
1. Davidorf IM. Femtosecond versus (gold) standard phacoemulsification. J Cataract Refract Surg. 2015;41:1124.

2. Nicoli CM, Dimalanta R, Miller KM. Experimental anterior chamber maintenance in active versus passive phacoemulsification fluidics systems. J Cataract Refract Surg. 2016;42:157-62.

3. Sharif-Kashani P, Fanney D, Injev V. Comparison of occlusion break responses and vacuum rise times of phacoemulsification systems. BMC Ophthalmol. 2014:14:96.

4. Chang JS, Ng JC, Chan VK, et al. Cataract Surgery with a New Fluidics Control Phacoemulsification System in Nanophthalmic Eyes. Case Rep Ophthalmol. 2016;7:218-26.

5. Kotb AM, Elawamry Al. Feasibility of the New Torsional Phacoemulsification Software Phacoemulsification (Ozil IP) in Hard Cataracts Asia Pac I Ophthalmol (Phila) 2013:2.372-4.

6. LiuY Zeng M LiuX et al Torsional mode versus conventiona ultrasound mode phacoemulsification: randomized comparative clinical study. J Cataract Refract Surg. 2007:33:287-92.

7. Gonen T, Sever O, Horozoglu F, et al. Endothelial cell loss: Biaxial small-incision torsional phacoemulsification versus biaxial smallincision longitudinal phacoemulsification. J Cataract Refract Surg. 2012;38:1918-24.

8. Helvacioglu F, Tunc Z, Yeter $C$, et al. Ozil IP torsional mode versus combined torsional//ongitudinal microcoaxial phacoemulsification. Eur J Ophthalmol. 2012;22:936-42.

9. Khokhar $\mathrm{S}$, Aron N, Sen S, et al. Effect of balanced phacoemulsification tip on the outcomes of torsional phacoemulsification using an active-fluidics system. J Cataract Refract Surg. 2017;43:22-8
10. Vasavada AR, Johar K, Sr., Praveen MR, et al. Histomorphological and immunofluorescence evaluation of clear corneal incisions after microcoaxial phacoemulsification with $2.2 \mathrm{~mm}$ and $1.8 \mathrm{~mm}$ systems. J Cataract Refract Surg. 2013;39:617-23.

11. Leon $\mathrm{P}$, Umari I, Mangogna $\mathrm{A}$, et al. An evaluation of intraoperative and postoperative outcomes of torsional mode versus Iongitudinal ultrasound mode phacoemulsification: a Metaanalysis. Int J Ophthalmol. 2016:9:890-7.

12. Tognetto D, D'Aloisio R, Cecchini P, et al. Comparative clinical study of Whitestar Signature phacoemulsification system with standard and Ellips FX handpieces. Int Ophthalmol. 2017; doi: 10.1007/s10792-017-0649-5. [Epub ahead of print].

13. Christakis PG, Braga-Mele RM. Intraoperative performance and postoperative outcome comparison of longitudinal, torsional, and transversal phacoemulsification machines. I Cataract Refract Surg. 2012;38:234-41.

14. Assil KK, Harris L, Cecka J. Transverse vs torsional ultrasound: prospective randomized contralaterally controlled study comparing two phacoemulsification-system handpieces. Clin Ophthalmol. 2015;9:1405-11.

15. Schmutz JS, Olson RJ. Thermal comparison of Infiniti OZil and Signature Ellips phacoemulsification systems. Am J Ophthalmol. 2010;149:762-7 e1.

16. Jensen JD, Shi DS, Robinson MS, et al. Torsional power study using CENTURION phacoemulsification technology. Clin Exp Ophthalmo 2016:44:710-3

17. Jensen JD, Boulter T, Lambert NG, et al. Intraocular pressure study using monitored forced-infusion system phacoemulsification technology I Cataract Refract Surg 2016:42:768-71.

18. Chen M, Chen M. Comparison of CDE data in phacoemulsification between an open hospital-based ambulatory surgical center and a free-standing ambulatory surgical center. Clin Ophthalmol. 2010;4:1287-9.

19. Solomon KD, Lorente R, Fanney D, et al. Clinical study using a new phacoemulsification system with surgical intraocular pressure control. J Cataract Refract Surg. 2016:42:542-9.

20. Chen $\mathrm{M}$, Anderson $\mathrm{E}, \mathrm{Hill} \mathrm{G}$, et al. Comparison of cumulative dissipated energy between the Infiniti and Centurion phacoemulsification systems. Clin Ophthalmol. 2015;9:1367-72.

21. Ryoo NK, Kwon JW, Wee WR, et al. Thermal imaging comparison of Signature, Infiniti, and Stellaris phacoemulsification systems. BMC Ophthalmol. 2013:13:53.

22. Zacharias J, Ohl CD. Fluid dynamics, cavitation, and tip-to-tissue interaction of longitudinal and torsional ultrasound modes during phacoemulsification. J Cataract Refract Surg. 2013;39:611-6.

23. Yesilirmak N, Diakonis VF, Sise A, et al., Differences in energy expenditure for conventional and femtosecond-assisted cataract surgery using 2 different phacoemulsification systems. J Cataract Refract Surg. 2017;43:16-21.

24. Day AC, Gore DM, Bunce C, et al. Laser-assisted cataract surgery versus standard ultrasound phacoemulsification cataract surgery. Cochrane Database Syst Rev. 2016;7:CD010735.

25. Chen X, Chen K, He J, et al. Comparing the Curative Effects between Femtosecond Laser-Assisted Cataract Surgery and Conventional Phacoemulsification Surgery: A Meta-Analysis. PLOS One. 2016;11:e0152088. 


\section{CENTURION ${ }^{\circledR}$ Vision System Important Product Information}

\begin{tabular}{|c|c|}
\hline Caution & 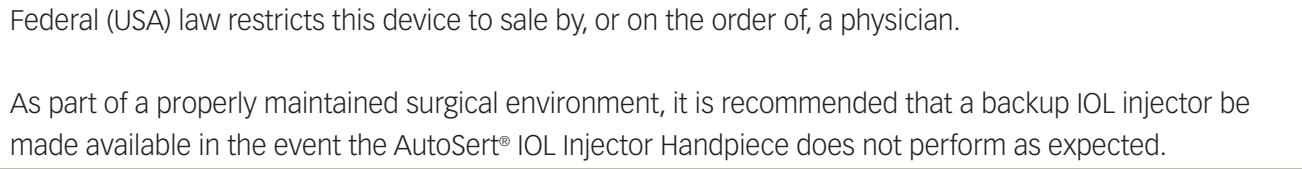 \\
\hline Indication & 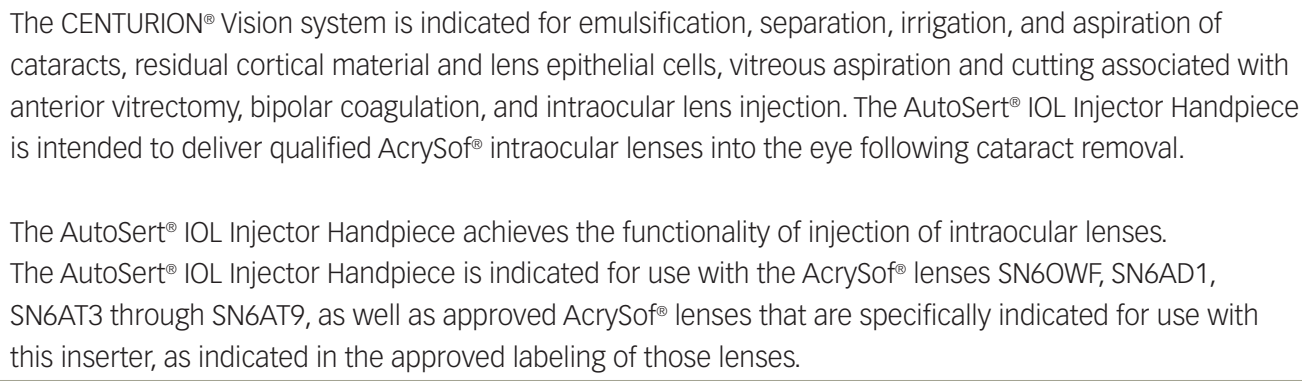 \\
\hline Warnings & $\begin{array}{l}\text { Appropriate use of CENTURION }{ }^{\circledR} \text { Vision System parameters and accessories is important for successful } \\
\text { procedures. Use of low vacuum limits, low flow rates, low bottle heights, high power settings, extended } \\
\text { power usage, power usage during occlusion conditions (beeping tones), failure to sufficiently aspirate } \\
\text { viscoelastic prior to using power, excessively tight incisions, and combinations of the above actions may } \\
\text { result in significant temperature increases at incision site and inside the eye, and lead to severe thermal } \\
\text { eye tissue damage. } \\
\text { Good clinical practice dictates the testing for adequate irrigation and aspiration flow prior to entering the } \\
\text { eye. Ensure that tubings are not occluded or pinched during any phase of operation. } \\
\text { The consumables used in conjunction with ALCON }{ }^{\circledast} \text { instrument products constitute a complete surgical } \\
\text { system. Use of consumables and handpieces other than those manufactured by Alcon may affect system } \\
\text { performance and create potential hazards. }\end{array}$ \\
\hline AEs/Complications & $\begin{array}{l}\text { Inadvertent actuation of Prime or Tune while a handpiece is in the eye can create a hazardous condition } \\
\text { that may result in patient injury. During any ultrasonic procedure, metal particles may result from } \\
\text { inadvertent touching of the ultrasonic tip with a second instrument. Another potential source of metal } \\
\text { particles resulting from any ultrasonic handpiece may be the result of ultrasonic energy causing micro } \\
\text { abrasion of the ultrasonic tip. }\end{array}$ \\
\hline ATTENTION & $\begin{array}{l}\text { Refer to the Directions for Use for the accessories/consumables and Operator's Manual for a complete } \\
\text { listing of indications, warnings, cautions and notes. }\end{array}$ \\
\hline
\end{tabular}




\section{INFINITI ${ }^{\circledR}$ Vision System}

\begin{tabular}{|c|c|}
\hline Caution & Federal law restricts this device to sale by, or on the order of, a physician. \\
\hline Indication & $\begin{array}{l}\text { The INFINITI }{ }^{\circledR} \text { Vision System is indicated for emulsification, separation, } \\
\text { and removal of cataracts, the removal of residual cortical material and lens epithelial cells, vitreous } \\
\text { aspiration and cutting associated with anterior vitrectomy, bipolar coagulation, and intra-ocular lens } \\
\text { injection. The INTREPID }{ }^{\circledR} \text { AutoSert }{ }^{\circledR} \text { IOL Injector Handpiece is intended to deliver qualified AcrySof }{ }^{\circledR} \\
\text { intraocular lenses into the eye following cataract removal. } \\
\text { The following system modalities additionally support the described indications: } \\
\text { - Ultrasound with UltraChopper }{ }^{\circledR} \text { Tip achieves the functionality of cataract separation. } \\
\text { - The INTREPID }{ }^{\circledR} \text { AutoSert }{ }^{\circledR} \text { IOL Injector Handpiece achieves the functionality of injection of intraocular } \\
\text { lenses. The INTREPID }{ }^{\circledR} \text { AutoSert }{ }^{\circledR} \text { IOL Injector Handpiece is indicated for use with AcrySof }{ }^{\circledR} \text { lenses } \\
\text { SN6OWF, SN6AD1, SN6AT3 through SN6AT9, as well as approved AcrySof }{ }^{\circledR} \text { lenses that are specifically } \\
\text { indicated for use with this inserter, as indicated in the approved labeling of those lenses. }\end{array}$ \\
\hline Warnings & $\begin{array}{l}\text { Appropriate use of INFINITI Vision System parameters and accessories is important for successful } \\
\text { procedures. Use of low vacuum limits, low flow rates, low bottle heights, high power settings, extended } \\
\text { power usage, power usage during occlusion conditions (beeping tones), failure to sufficiently aspirate } \\
\text { viscoelastic prior to using power, excessively tight incisions, and combinations of the above actions may } \\
\text { result in significant temperature increases at incision site and inside the eye, and lead to severe thermal } \\
\text { eye tissue damage. } \\
\text { Adjusting aspiration rates or vacuum limits above the preset values, or lowering the IV pole below the } \\
\text { preset values, may cause chamber shallowing or collapse which may result in patient injury. } \\
\text { When filling handpiece test chamber, if stream of fluid is weak or absent, good fluidics response will be } \\
\text { jeopardized. Good clinical practice dictates the testing for adequate irrigation and aspiration flow prior to } \\
\text { entering the eye. }\end{array}$ \\
\hline AEs/Complications & $\begin{array}{l}\text { Use of the INFINITI }{ }^{\circledR} \text { Vision System handpieces in the absence of irrigation flow and/or in the presence } \\
\text { of reduced or lost aspiration flow can cause excessive heating and potential thermal injury to adjacent } \\
\text { eye tissues. }\end{array}$ \\
\hline ATTENTION & Refer to the directions for use for a complete listing of indications, warnings and precautions. \\
\hline
\end{tabular}

(C) 2018 Novartis 2/18 US-CNT-18-E-0115 